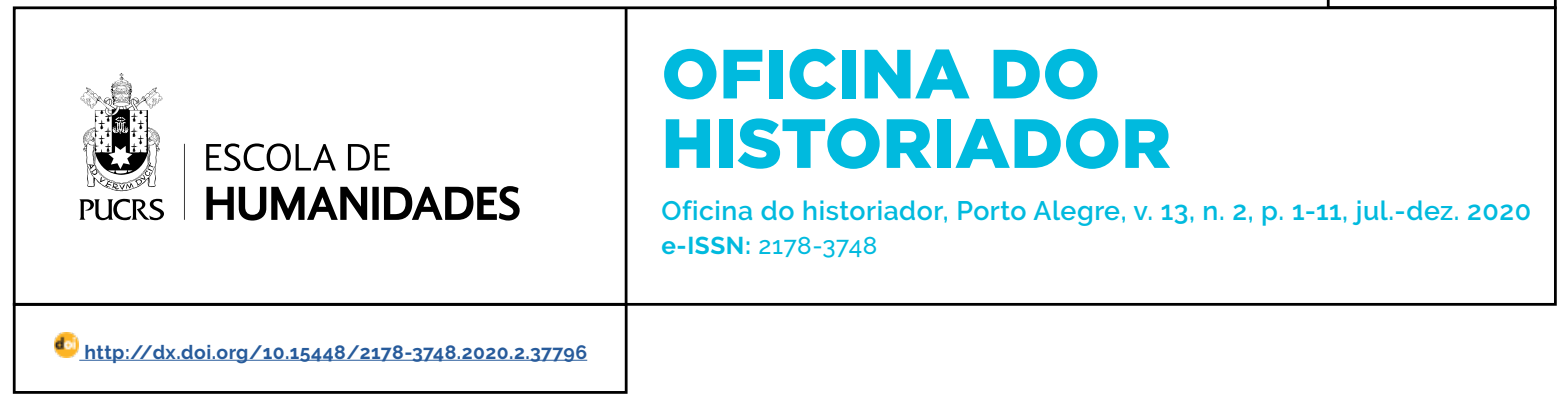

SEÇÃO: DOSSIÊ

\title{
Potencialidades de pesquisa em História Ambiental e a questão indígena
}

\author{
Research potentials in Environmental History and the indigenous issue
}

\section{Angela Rebelo da Silva Arruda $^{1}$ \\ orcid.org/0000-0002-4244-5652 angelarebeloarruda@gmail.com}

Recebido em: 22/4/2020. Aprovado em: 29/5/2020. Publicado em: 21 dez. 2020.
Resumo: A História Ambiental ainda é relativamente nova no empreendimento historiográfico, portanto, cabe discutir sobre suas potencialidades de pesquisa. No Brasil, pode-se dizer que há uma vastidão de fontes disponiveis que nos antecedem há alguns séculos e que precisam ser exploradas para o avanço desse campo da história. Além disso, as peculiaridades da formação histórica do povo brasileiro necessitam fundamentalmente ser consideradas. Neste sentido, destacamos uma abordagem sobre a temática indigena, pois que os dilemas ambientais resultam de uma colonização predatória na qual herdamos esse mesmo sentido de desenvolvimento para o país. O objetivo deste artigo é, portanto, chamar atenção para fontes disponiveis, a exemplo do estado do Amazonas: além de oferecer algumas reflexões sobre o homem indigena brasileiro para a construção de uma história ambiental. Para isso, procedemos à análise de trechos de periódicos e outros tipos de manifestação social de protesto, controle e preocupação com o meio natural; como também, na análise da questão indígena na história ambiental. Esperamos com isso, contribuir com o desenvolvimento de pesquisas relevantes na área.

Palavras-chave: História Ambiental. Amazonas. Indigenas.

Abstract: Environmental History is still relatively new in the historiographic enterprise, so it is worth discussing its research potential. In Brazil, it can be said that there are a vast number of sources available that predates us by some centuries and that needs to be explored to advance this field of history. In addition, the peculiarities of the historical formation of the Brazilian people fundamentally needs to be considered. In this sense, we highlight an approach on the indigenous theme, since the environmental dilemmas result from a predatory colonization in which we inherited this same sense of development for the country. The purpose of this article is, therefore, to draw attention to available sources, such as the state of Amazonas; besides offering some reflections on the Brazilian indigenous man for the construction of an environmental history. For that, we proceeded with the analysis of excerpts from journals and other types of social manifestation of protest, control and concern with the natural environment; as well as in the analysis of the indigenous issue in environmental history. With that, we hope to contribute to the development of relevant research in the area.

Keywords: Environmental History. Amazonas. Indigenous.

\section{Introdução}

A partir da Primeira Guerra Mundial, as ciências sociais se convenceram a rejeitar análises com aspectos físico-naturais (raça, anatomia, cor, clima, vínculos com a terra) privilegiando exclusivamente cultura e sociedade, devido ao agressivo racismo-territorialismo nazista (DRUMMOND, 1991, p. 177-197). Todavia, movimentos sociais ambientalistas, desde as últimas 
décadas do século $X X$, despontaram no meio de crises ambientais localizadas, desafiando as ciências sociais a ultrapassarem seu marco puramente 'humanista', pois "não era mais possivel pensar na sociedade humana sem ancoragem no mundo natural" (DRUMMOND, 1991, p. 180).

De acordo com Pádua (2010), o primeiro curso universitário de maior repercussão com o título de História Ambiental atendeu a "voz das ruas" que clamavam por responsabilidade ambiental, sendo ministrado pelo historiador culturalista Roderick Nash em 1972 na universidade da Califórnia, em Santa Bárbara. Estados Unidos, França e Inglaterra tomaram a dianteira por alguns historiadores "reformistas" a fim de incorporar as variáveis naturais nas pesquisas tratando de colocar "a sociedade na natureza" (DRUMMOND, 1991, p. 180).

Contudo, com relação às disciplinas sociais como a história ambiental, não se trata de aderir a um determinismo natural unilateral, uma vez que "a cultura humana age sobre o meio físico-material, propiciando significados e usos complexos dos seus elementos" (DRUMMOND, 1991, p. 181). Na mudança de paradigma, compreende-se que embora tenha havido razões para não enfrentar análises das bases naturais da sociedade, fugindo do determinismo do século XIX, o cientista social "dá às 'forças da natureza' um estatuto de agente condicionador ou modificador da cultura" (DRUMMOND, 1991, p. 181).

No estudo dos recursos naturais, por exemplo, é possivel analisar o papel das culturas que afinal são elas próprias que os identificam e os avaliam, e embora os recursos não se imponham à cultura, estimulam e vetam caminhos, ou seja, "os historiadores ambientais fogem do determinismo natural, tecnológico e geográfico, mas se recusam a ignorar a influência dos quadros naturais na história e na cultura das sociedades humanas" (DRUMMOND, 1991, p. 183).

No Brasil, a história ambiental, embora incipiente, já possui referências muito relevantes, a exemplo de Costa (2002), Pádua (2002), Jorge (2006) e Franco (2012), só para citar alguns. Pode-se dizer que o estudo dessa grande área é repleto de potencialidades e sua importância é inestimável.
Contudo, os desafios são gigantescos no enfrentamento de questões complexas e impõem uma reflexão mais aprofundada, a exemplo do que sugeriu Warren Dean (1996, p. 379) com relação à devastação de florestas: uma história de holocausto que está a deserdar todos nós e as crianças do futuro, há gerações. Tendo a história ambiental sua origem no protesto popular, cientificamente bem fundamentado e voltado especialmente à sensibilização de agressões a outras formas de vida (não humanas), cabe avançar ainda mais em pontos, aparentemente, muito poucos explorados.

Aqui, chama-se atenção para a existência de material disponivel há séculos que certamente haverão de compor grandes pesquisas no porvir, a exemplo da região amazônica, onde inquietações de alguns setores da sociedade amazonense e periódicos locais revelam que já havia uma preocupação com o meio natural. Analisar-se-á, então, algumas fontes que mostram indícios interessantes e que certamente potencializam o avanço nas pesquisas em história ambiental.

Outro aspecto considerado relevante é a reflexão inadiável sobre o lugar que a história ainda tende a colocar a cultura indígena. Considera-se, portanto, a questão indígena indispensável na abordagem da história ambiental brasileira e espera-se contribuir neste trabalho com algumas provocações. Assim, a temática indigena é aqui tratada a fim de estimular alguns caminhos de pesquisa.

\section{Potencialidades de pesquisa no Amazonas}

A incorporação de uma análise biofísica junto com outras dimensões de nossas abordagens econômica, culturais, sociais e políticas - poder-se-á enriquecer com amplitude a investigação histórica, especialmente por se tratar do estado do Amazonas que historicamente possui, como os demais estados da Amazônia, seus destinos voltados às múltiplas disputas envolvendo a questão ambiental em complexas relações de poder, com oposições e nuances as mais variadas, entre os grupos sociais e seus valores constituidos que descortinam aspectos altamente relevantes na nossa história. "O crescimento acadêmico recente 
da história ambiental, ao menos em parte, se explica exatamente por sua capacidade concreta para ampliar a análise histórica e trazer novas perspectivas para o estudo de antigos problemas historiográficos" (PÁDUA, [2010]).

Na capital amazonense, um recente conflito social, demonstrou um embate de valores culturais que abalou a comunidade local. Já é possivel enxergar no pequeno trecho abaixo a afetação da vida cotidiana, não apenas para os diversos sujeitos históricos, como para o meio natural, a fauna e a flora, parte integrante das memórias e das histórias daqueles que cresceram em torno de seu patrimônio ou mesmo dos recém-chegados, os jovens, prontos ao combate:

Pedimos desculpas às gerações passadas e futuras, aos moradores de Adrianópolis, desde os mais humildes até os residentes nos prédios de alto padrão que sofreram igualmente com o desmatamento: às idosas senhoras que choraram pela preservação da área de lazer de suas infâncias; às donas de casa indignadas com o destino das cotias, das preguiças, dos gaviões, e aos jovens liderados por Gustavo Nogueira, que nos procuraram para ajudá-los a salvar a floresta. Infelizmente rechaçamos suas ideias de 'amarrarem-se às árvores', convencendo-os, ilusoriamente, que o caminho correto seria denunciar aos órgãos ambientais e ao Ministério Público (WANDELLI, [2008]).

O trecho da carta aberta de Elisa Wandelli (pesquisadora da Empresa Brasileira de Pesquisas Agropecuária - Embrapa) contra a devastação do fragmento florestal 'Igarapé da Magistral' realizado no dia mundial do meio ambiente em 2007, que mesmo com o apelo popular, foi autorizado pelos órgãos ambientais (Secretaria Municipal de Meio Ambiente e Sustentabilidade - SEMMAS e Instituto de Proteção Ambiental do Amazonas - IPAAM) para a construção de um shopping center, apresenta uma experiência de confronto. Desfilando uma série de valores: nostalgia, revolta, frustração, paixão e compaixão por cidadãos comuns, e agentes públicos sensiveis à causa ambiental. A região certamente necessita explorar uma abordagem em história ambiental, o que exigirá o enfrentamento de questões inadiáveis que não se trata de invadir a jurisdição de outras ciências, mas de não fugir da diminuição de nossas lacunas historiográficas.
Contudo, no estado do Amazonas, (mas não somente nele) as motivações dos movimentos ambientalistas de agora são inquietações muito antigas. "Na verdade, preocupações relacionadas a um cuidado com a natureza podem ser encontradas em tempos mais remotos, remontando aos fins do periodo colonial" (FRANCO; DRUMMOND, 2009, p. 60). Mas, "formulações mais próximas do moderno discurso conservacionista só aparecem no Brasil nos fins do século XIX e principios do XX" (FRANCO; DRUMMOND, 2009, p. 60).

Na Resolução n. ${ }^{\circ} 54$ de 4 de julho de 1855 . encontra-se a proibição da manipulação da manteiga de ovos de tartaruga em algumas praias da província e estabelece regras para a policia nos lugares onde é permitido exercê-la apresentando todo um mecanismo de controle da situação como meio de evitar a corrupção dos guardas com multa aos subornadores de "duzentos mil réis, a qual será commutada em seis mezes de prizão simples, não tendo os infractores com que a pagarem" (ESTRELLA DO AMAZONAS, 1855, p. 2). Por conseguinte, "as Camaras Municipais collocarão Guardas nas praias de seus respectivos municipios d'esde o começo da desovação até brotarem, e se retirarem ao rio as tartaruguinhas..." (ESTRELLA DO AMAZONAS, 1855, p. 2),

Como também se exemplifica já no $1^{\circ}$ artigo do decreto de Lei $n^{\circ} 102$, de 8 de julho de 1859 , do $1 .^{\circ}$ vice-presidente da província do Amazonas, Manuel Gomes Correa de Miranda:

Art. $1^{\circ}$ Fica prohibido em toda a Provincia: $\S$
$1 .^{\circ}$ Aconducção de tartarugas em canôas ou
jangadas de modo que fiquem apinhoadas ou
cavalgadas umas sobre outras, e por isso em
numero maior de uma por cada 4 arrobas, que
lotar a canoa, ou de treze por cada tonellada.
Os infractores soffrerão a multa de 1.000 reis,
ou meio dia de prisão, por cada tartaruga ex-
cedente do numero fixado por arrobas ou
tonelladas (ESTRELLA DO AMAZONAS, 1859).

Pode-se afirmar, portanto, que as precauções ambientais não são exatamente novas no universo da modernidade que assistiu a eclosão de movimentos sociais organizados, porque isso implica em valores dos sujeitos que vão construindo a história humana era após era, mesmo que com relação às preocupações dessa natureza esteja, 
quase sempre, longe de significar um pensamento hegemônico. O cuidado com as tartarugas pelo poder público certamente não foi o único caso nesse sentido. Tanto é que quase cem anos depois das leis provinciais, mais precisamente em 1938, manifestações de protesto contra a agressão da fauna e flora amazônica propagaram-se por meio da Revista Agronômica através do artigo do Prof. Agnello Bittencourt intitulado "Economia destructiva" como pode ser observado no trecho a seguir:

E, no meio dos prodigios naturaes, não deixa de apparecer o homem, como usufructuario de uma estupenda fortuna, que não creou e que procurou destruir, atravez dos tempos. Na ancia de enriquecer, o extractor vae devastando e annullando as fontes da producção. Abatemse as florestas e matam-se os animais, sem se imaginar os effeitos dessa atitude satanica. Todas as leis prohibitivas têm sido letra morta, por falta de uma educação economica, isto é, de um sentido utilitario e humano dos beneficios da natureza. Ha mais de meio seculo, os Poderes publicos trataram de defender as praias em que as tartarugas faziam seus 'taboleiros'. A industria da manteiga de ovos, cuja exportação, em pótes de barro, figura nas estatisticas de outr'ora, motivava o assalto áquelles centros de creação, dando em resultado o desapparecimento dos grandes viveiros de Kelonios do Solimões, Purus, Madeira e outros rios do Estado (BITTENCOURT, 1938, p. 33-34).

Nesse mesmo periódico chama atenção também a nota: "a 'Revista Agronomica' está num lugar de destaque preenchendo enormissima lacuna; e embora, infelizmente, ainda mal comprehendida, ha de ser em breve, uma realidade" (BITTENCOURT, 1938, p. 34), pois que revela que a preocupação ambiental estava longe de compor as prioridades do poder público em 1938, o que não impediu que houvesse manifestação da sociedade.

Por fim, "[...] a produção amazônica se ressente de trabalhos que ressaltem as interações humanas com o mundo natural" (LIMA, 2017, p. 93). A história ambiental está presente na vida dos amazonenses, uma vez que se relaciona com as "necessidades simbólicas e emocionais" (LIMA, 2017, p. 93) de sua sociedade. Essa história pode ser contada à escolha do historiador. Sua relevância é legitimada pelo fato de o tema permanecer desafiador ao longo dos séculos e ter desencadeado um significativo movimento ambientalista com suas vitórias e derrotas dentro dos movimentos sociais que compõem a construção dos destinos daquele estado, como da história do Brasil.

Seria muito interessante conhecer quais são as especificidades, os problemas, as motivações em que as politicas ambientais foram criadas e implementadas, bem como, os discursos de cada época correspondente, ao longo dos séculos, para se chegar à postura que a sociedade possuía, de maneira política, institucional, ativista (aspectos não necessariamente separados), e de que forma foi encontrando meios para responder aos desafios de gerenciamento dos recursos naturais, de preservação e/ou conservação da natureza e aos problemas decorrentes da urbanização das cidades mediante as agressões ao meio ambiente.

Também o contexto intelectual, as articulações, as referências, as inspirações nacionais e internacionais e o conjunto de apropriação desses elementos onde se desenvolveu a preocupação com as questões ambientais. Os pontos de embate entre os grupos sociais com valores opostos com relação à preocupação com a natureza e como se deram essas experiências nas esferas institucionais, científicas, governamentais e não governamentais (ONGs).

Falando agora não exclusivamente sobre o estado do Amazonas, mas também a ele se aplica, "de fato, boa parte do material da história ambiental está disponivel há gerações, talvez há séculos, e agora está sendo apenas reorganizado à luz das experiências recentes" (WORSTER, 1991, p. 201). Não cabe mais ignorar que o aspecto ambiental sempre fez parte da nossa história, desde o empreendimento mercantil do colonizador que aqui se esbaldou em recursos naturais, sua ambição e motivação ano após ano na exploração de riquezas e de povos que aqui já habitavam estabelecendo com eles relações de poder, com histórias de resistências e confrontos.

Também na construção das cidades que em qualquer lugar causou impacto ambiental e começou a contar a história das divisões entre ricos e pobres no Brasil, e nas doenças que atingiam a todos, mesmo os mais abastados, a diferença era qual grupo morria mais por ser mais bem 
assistido e viver em áreas ambientalmente controladas, como aborda o historiador Janes Jorge (2006) sobre o rio Tietê.

Hoje o avanço perverso do capital é ainda mais capaz de putrefazer setores do poder público que deveriam defender o cumprimento das leis ambientais. Mas essa história também apresenta seu lado de resistência entre aqueles que compreendem os reais interesses em nome do "progresso" e nadam contra a corrente. São homens e mulheres que vêm fazendo essa história e trilham em destaque nos eventos cruciais das leis de proteção ambiental hoje constituidas. Conquistas essas que não podem passar despercebidas na escrita do historiador.

Na medida em que se incorporam os aspectos biofísicos nas análises da história, esclarecem-se as dimensões econômicas e culturais de uma sociedade de maneira muito mais completa. 0 trabalho de Victor Leonardi (1999, p. 272) na Amazônia é um bom exemplo dessa eficácia, afinal como desconsiderar os aspectos de uma região fundamentalmente voltada aos recursos naturais, ao extrativismo, ao transporte fluvial, sem evidenciar o solo, a floresta e os rios? Na Amazônia fica ainda mais dificil imaginar homens e mulheres "pairando acima da natureza e do meio ambiente, ou como se as populações ribeirinhas não tivessem nada a ver com as características físico-químicas do solo no qual trabalham e com a qualidade da água do rio às margens do qual habitam!" (LEONARDI, 1999, p. 15).

O historiador brasilianista americano, Warren Dean, contribuiu significativamente quanto a trabalhos de história ambiental. No Brasil, ele se destacou mais amplamente com um estudo sobre a mata atlântica e outro sobre a seringueira na Amazônia, aplicando a evidência ecológica na análise da história econômica da região a fim de compreender historicamente os regimes agricolas, dando a real importância ao aspecto biológico e as condições ecológicas de produção ao invés do, geralmente referido, processo industrial. Dean dessa maneira assumiu que as transformações "provocadas pelos seres humanos nas relações ecológicas não são inconsequentes, dando a elas um caráter de acontecimento histórico indissociáveis das mudanças sócio-politicas que se sucedem à intervenção humana na natureza" (OLIVEIRA, 2010, p. 114-115).

A percepção humboldtiana da interdependência entre as espécies que formou a tão avançada concepção de ecologia, evidencia que a espécie humana só poderá se manter enquanto reprodutora de sua espécie, "os seus filhos sobrevivem ou morrem de acordo com a qualidade do alimento, do ar, da água e com a quantidade de microorganismos que constantemente penetram seus corpos" (WORSTEN, 1991, p. 206), sendo os seres humanos "parte inseparável da ordem ecológica do planeta" (WORSTEN, 1991, p. 206). Assim, "qualquer reconstrução dos ambientes do passado tem que incluir não apenas florestas e desertos, jibóias e cascavéis, mas também o animal humano e o seu sucesso ou fracasso no ato de se reproduzir" (WORSTEN, 1991, p. 206).

E como grupos humanos, os movimentos sociais são flexibilizados numa uniformidade estratégica que embora pareçam diluidos, fortalecem-se a partir de vínculos solidários diante das situações de confronto que ameaçam os seus modos de vida. As especificidades dos movimentos sociais na Amazônia se caracterizam por esse tipo de aglutinação. Logo, povos indígenas, seringueiros, castanheiros, quilombolas, entre tantos outros, ora se denominam de acordo com o contexto, 'remanejados', 'deslocados', 'assentados' etc., e ora se submetem às identidades mais genéricas como 'ribeirinhos' e 'povos da floresta'. Por outro lado, a fim de maior representatividade politica, concentram-se em 'associações', 'comissões' e 'comunidades' como 'unidades de mobilização' constituindo-se em 'forças sociais' (ALMEIDA, 1994, p. 521).

"Nesta ordem elas não representam apenas simples respostas e problemas localizados. Suas práticas alteram padrões tradicionais de relação política com os centros do poder e com instâncias de intermediação" (ALMEIDA, 1994, p. 524), desse modo, "possibilitando a emergência de lideranças que prescindem dos que detêm o poder local" (ALMEIDA, 1994, p. 524). Não se trata, no entanto, da motivação de tomada do poder político, mas, 
camuflado numa generalização "o localismo de suas reivindicações e mediante estas práticas de mobilização aumentam seu poder de barganha face ao governo e ao Estado" (ALMEIDA, 1994, p. 524).

No Estado Territorial Moderno impera a concepção de "Estado como escala única da vida política, uma só fonte de poder, uma só comunidade política, uma só possibilidade de organização da comunidade política, uma só unidade representativa do político" (BECKER, 1994, p. 105). Mas, a crise ambiental e a revolução tecnológica vêm afetando diretamente a integridade do Estado Territorial Moderno a partir de fatores sociais e de movimentos antis-sistêmicos. "Trata-se de projetos culturais, projetos alternativos, explorações culturais inovadoras que desafiam a dominância da civilização ocidental, da cultura ocidental" (BECKER, 1994, p. 105), logo, "a diversidade cultural se desloca da unidade do Estado, as diferentes culturas reclamam seu direito à diferença e o direito a seu território dentro do território do Estado" (BECKER, 1994, p. 105).

Apesar do Estado ter um papel fundamental na economia e no meio ambiente frente aos problemas gravissimos demonstrados por dados alarmantes que a atualidade apresenta - como elevados indices de desmatamento que afetando o clima causam o efeito estufa; o altíssimo grau de poluição planetária advindas do Brasil como um dos principais países responsáveis por emissões de $\mathrm{CO}^{2}$; o problema do agronegócio e da concentração fundiária - não são apenas suas politicas governamentais que garantirão a floresta em pé, reprimindo os desmatamentos, mas o "fortalecimento de associações e formas organizativas comunitárias e aos meios de consolidação dos conhecimentos e saberes práticos dos povos e comunidades tradicionais que mais conservam os recursos florestais e hidricos" (ALMEIDA, 2010, p. 125-126), uma vez que são esses povos que possuem "um conhecimento profundo dos ecossistemas dos biomas, enfim, e da biodiversidade. Este conhecimento, mesmo sob as pressões constantes dos que devastam, persiste sendo um fator essencial de preservação" (ALMEIDA, 2010, p. 125-126).
Assim, dentre os povos tradicionais, essenciais na questão da preservação, prossegue-se a uma abordagem sobre povos indigenas, pois, trata-se de uma reflexão fundamental para os caminhos da história ambiental brasileira.

\section{O índio e a história ambiental}

Antes de tudo, é consenso que a multidisciplinariedade e a interdisciplinaridade fundamentam o arcabouço que constitui a história ambiental. No entanto, ao abordar aqui sobre povos indígenas, quero desvencilhar um pouco a ideia de que somente fazendo uso da antropologia, é que se pode adentrar no tema indigena, pois suas especificidades costumam demandar ferramentas antropológicas; e assim, contrariar a ideia de Varnhagen que em 1854 declarou: "de tais povos na infância não há história, só há etnografia" (VARNHAGEN, 1981 apud MONTEIRO, 2001, p. 28).

O meu convite é que se olhe por alguns instantes o homem indigena, como homem histórico, já que inserido no processo histórico, pois a história não faz distinção entre que tipo de homem age no tempo. Que se compreenda, de uma vez por todas, que "nós não somos as únicas pessoas interessantes no mundo, somos parte de um todo. Isso talvez tire um pouco a vaidade dessa humanidade que nós pensamos ser" (KRENAK, 2019, p. 30-31). Hoje, no Brasil, o panorama indigena necessita ser mais bem examinado.

Não necessariamente, precisamos conhecer linguas especificas e tentar se inserir no espaço organizado de uma aldeia ou procurar um convívio que nos aproxime do cotidiano entre comunidades indigenas.

Diferentemente de muitos paises nas Américas,
onde a presença indigena se mantém forte na
articulação das identidades nacionais, o lugar
dos índios no Brasil continua sendo conjugado,
no mais das vezes, no tempo passado. Hoje,
uma minoria absoluta, a população indigena
atual mal chega ao o,20\% da população do
pais como um todo de acordo com a estatistica
oficial, que ainda a trata como 'remanescente'.
Ainda assim, por trás dessa cifra infima floresce
um rico painel de diversidade - mais de 200
grupos étnicos que conservam mais de 170
linguas distintas - e um legado histórico do
qual o país ainda não se deu conta. Apesar
de fundamentada em algumas verdades, a 
crônica da destruição e do despovoamento já não é mais aceitável para explicar a trajetória dos povos indígenas nestas terras. O que se omite com tal abordagem, são as múltiplas experiências de elaboração e reformulação de identidades, que se apresentaram como respostas criativas às pesadas situações de contato, contágio e subordinação. O caminho ainda é longo e bastante incerto; mas vários antropólogos e historiadores já vêm dando passos na direção certa (MONTEIRO, 2001, p. 78).

Abandonemos o exotismo para examinar o índio como homem histórico brasileiro. É preciso tirar os indigenas dos bastidores porque também são constitutivos de Brasil, enquanto grande comunidade de povos distintos.

Parte significativa do povo indígena demandou, sobretudo de suas lideranças, a inserção estratégica no espaço não indígena. Estes estão por toda parte, como nas universidades, são alunos, professores, doutores; utilizam de tecnologias não indígenas; conquistam enfim, outro tipo de capital intelectual e cultural, além dos seus característicos sem, contudo, abandoná-los. Ao contrário, compreendem que a manutenção de seus modos de vida e a preservação de sua língua materna fortalece o movimento indigena na permanente luta pela manutenção dos seus direitos conquistados, além da luta por outros direitos

Logo, pelo não abandono de seu próprio capital cultural, possuem maneiras próprias de avaliar a interação homem/natureza. Por outro lado, quanto aos não indigenas, secularmente perdem a oportunidade de apreender os saberes desses povos. Talvez seja a razão pela qual "a contemplação da natureza tem tido poucos adeptos no Brasil. O prestígio da urbanidade, transmitido pelos portugueses como meio de confirmar seu status superior em um ambiente estranho, sobrevive quase que inato" (DEAN, 1996, p. 379).

Tanto é assim que

a Conferência das Nações Unidas sobre Meio Ambiente e Desenvolvimento, realizada no Rio de Janeiro em junho de 1992, legou para a posteridade algumas das mais utilitaristas, para não dizer mesquinhas, concepções sobre o mundo natural dos tempos modernos. A diversidade da vida foi ali rotulada como 'recursos genéticos', as florestas foram caracterizadas como um recurso renovável e a preservação foi classificada como um verbete de uso sus- tentável. [...] Os governos do Terceiro Mundo, supostamente representantes de muitos grupos 'grupos tradicionais', acharam adequado abraçar os pressupostos e prescrições mais materialistas (DEAN, 1996, p. 378).

"A respeito dessa ideia de recurso que se atribui a uma montanha, a um rio, a uma floresta, em que lugar podemos descobrir um contato entre as nossas visões que nos tire desse estado de não reconhecimento uns dos outros?" (KRENAK, 2019, p. 51). Quando consideramos a visão sobre a relação homem/natureza, como aquilo que é próprio dele (o índio) e aquilo que é próprio nosso (o não indio), ignoramos que somos uma só humanidade, a diferença é o caminhar que insiste em nos (os não índios) separarmos da terra absurdamente.

Os únicos núcleos que ainda consideram que precisam ficar agarrados nessa terra são aqueles que ficaram meio esquecidos pelas bordas do planeta, nas margens dos rios, nas beiras dos oceanos, na África ou na América Latina. São caiçaras, indios, quilombolas, aborígenes - a sub-humanidade (KRENAK, 2019, p. 21).

É seguramente equivocado não avaliar o índio enquanto homem histórico e não perceber que muitos dos nossos impasses em história ambiental poderiam ser totalmente eliminados se nos inteirássemos mais de saberes indígenas, ao invés de persistir numa separação de humanidades que destina a esses povos a "sub-humanidade", quando, por exemplo, acontece de, comodamente, atirarmos a temática indígena exclusivamente no colo da antropologia, como se também não fosse constitutiva da história.

Quando historiadores agem assim, compactuam com a "abstração civilizatória" que "suprime a diversidade, nega a pluralidade das formas de vida, de existência e de hábitos. Oferece o mesmo cardápio, o mesmo figurino e, se possivel, a mesma língua para todo mundo" (KRENAK, 2019, p. 23). O ponto nevrálgico consiste em que

algumas das ações dos humanos em relação as outras espécies não fazem ainda parte das reflexões éticas de todos os seres humanos. Talvez fosse necessário pensar algumas dessas ações como genocídios ou mesmo como sendo uma guerra travada pelos humanos contra outras espécies (ARRUDA; COLACIOS, 2019, p. 68). 
Afastados de reflexões éticas que muito deixam a desejar entre não indios, parece distante acatar a provocação crítica e crucial de Warren Dean (1996, p. 379), "não deveria esse holocausto produzido pelo homem ser relatado de geração para geração? Não deveria o manual de história aprovado pelo Ministério da Educação começar assim: 'Crianças, vocês vivem em um deserto; vamos thes contar como foi que vocês foram deserdadas'?"

Não há lugar algum que se possa ir, em termos de história ambiental, sem colocarmos o dedo na ferida, sem refletirmos sobre a separação ilusória homem/natureza que apenas nos faz consumidores, perdendo assim valores fundamentais, afinal "para que ter cidadania, alteridade, estar no mundo de uma maneira crítica e consciente, se você pode ser um consumidor? Essa ideia dispensa a experiência de viver numa terra cheia de sentido, numa plataforma para diferentes cosmovisões" (KRENAK, 2019, p. 24-25). Engrossaremos o coro do discurso dos "recursos naturais" ou do "desenvolvimento sustentável" como "jargão e hipocrisia" (DEAN, 1996, p. 378) tendo o interesse próprio como a única motivação?

A história ambiental, inicialmente surgida com vínculos morais e politicos derivados dos movimentos ambientalistas, conseguiu afirmar seus compromissos metodológicos. Mais recentemente, alguns pensadores têm definido esse campo como uma 'história das relações dos seres vivos humanos e não humanos', o que significa um descentramento da agência histórica exclusivamente centrada no humano. Ora, isso coloca a seguinte questão: se esses outros seres vivos participam da construção humana, quais seriam os seus direitos e, no caso de um evidente "genocídio", a devastação, como os historiadores, os homens do tempo presente, deveriam agir? (ARRUDA; COLACIOS, 2019, p. 90).

Seria a questão de Arruda e Colacios um impasse epistemológico para os historiadores ambientais? No mínimo, um grande desafio para os que pretendem fazer uso da ousadia sem a qual não se pode avançar no desbravamento desse campo da história. Porém, talvez em outro contexto - onde a humanidade não é restrita aos seres humanos - portanto, a história caminharia de uma maneira diferente, esse impasse simplesmente não existisse. Imaginemos a seguinte situação: sou uma india de etnia tal e busquei novas fer- ramentas educacionais fora de minha aldeia ou comunidade, escolhi o curso de história e nele segui carreira acadêmica, sem, contudo, jamais deixar para trás a minha cosmovisão, então, será que eu teria as mesmas dificuldades no enfrentamento de questões como essa, ou seja, quanto ao reconhecimento dos direitos dos outros seres vivos e notar a devastação como um ato genocida para os múltiplos biomas aniquilados?

Refletir sobre isso não significa, contudo, que apenas emprestando os olhos dos povos indigenas teriamos legitimidade para avançar no sentido de uma história ambiental que amplia seus horizontes. A questão é que não se trata de um problema de interpretação das coisas, mas das coisas como elas são. Enxergar o homem índio histórico tanto quanto qualquer um de nós, não índios, poderia iluminar a resolução desses e outros impasses.

\begin{abstract}
[...] uma simbiose das duas culturas, retirando da antropofágica o seu desenvolvimento científico e da indigena o seu desenvolvimento espiritual - nesse ecletismo teríamos talvez a sociedade ideal, para, preservando a vida no planeta e cultivando o aperfeiçoamento da pesquisa científica, prepararmos o homem para ocupar todo o sistema planetário e desembarcar em outras galáxias na procura do Absoluto (CARREIRA, 1978, p. 15).
\end{abstract}

As várias culturas indigenas existentes na Amazônia e no Brasil possuem o seu habitus cultural mal compreendido pela sua direta associação ao atraso quando se fala de desenvolvimento. Isso de certa forma está incorporado, infelizmente, no habitus do não índio brasileiro que de modo geral, faz essa associação negativa e que é um reflexo do lugar destinado à importância das questões ambientais. E por isso mesmo, deixam de fora os aspectos intrinsecos do meio natural.

Todo esse conjunto tem carregado uma guerra secular do indigena para com seu posicionamento social enquanto constitutivo do povo brasileiro, resguardada a manutenção de seus modos de vida e de seus direitos duramente conquistados e permanentemente ameaçados. A violência física e simbólica nunca os abandonou, mas eles sempre estiveram no combate no campo social, por reconhecimento, legitimidade e autonomia a partir de alianças estratégicas com o campo científico e político. 
Condenamos eloquentemente o comportamento piegas e ridículo que se pretende no relacionamento com o índio. Tem sido até hoje a cultura indigena tratada com piedade, como se seus integrantes necessitassem da caridade da Sociedade Antropofágica. O indio não precisa da caridade e nem da piedade de uma civilização que se entredevora, de uma sociedade que se precipita no abismo do egocentrismo. O que o índio precisa é ser preservado no seu habitat, no seu caldo de cultura, onde se realize em plenitude e possa oferecer a sua contribuição válida à sociedade de consumo (CARREIRA, 1978, p. 15).

Compreender as preocupações ambientais - apenas - por solidariedade para com as comunidades indigenas, ou não indígenas, diretamente dependentes de seus recursos naturais para a sobrevivência (física, cultural e espiritual) é esquecer que sem o fabrico se vive, sem o alimento não, sem a indústria se vive, sem a terra não. O alimento (terra, ar, água) sempre há de ser vital e todos os setores econômicos da sociedade independentemente do grau hierárquico, posição, status, capacitação técnico-científica e outros, dele dependem fundamentalmente. Logo, as regiões industrializadas também, quer se queira quer não, estão subordinadas à regiões produtoras de alimentos.

Há ainda que se considerar a disputa simbólica da preservação da biodiversidade tomada pelo campo da ciência, pois ela reflete a forma como a comunidade científica vem se relacionando com esses povos.

\begin{abstract}
Hoje, os ocidentais pregam que tudo deve ser preservado em nome da 'ciência', e com este argumento retiram das comunidades indigenas todo e qualquer controle que tenham sobre o material genético essencial para a sua sobrevivência. Exemplos dessa exploração está no fato de que $68 \%$ das sementes usadas na agricultura, que um dia foi manipulada pelos indios, coletados e desenvolvidos pelos paises em desenvolvimento, estão depositados em bancos genéticos dos paises industrializados ou em Centros de Pesquisas Internacionais de Agricultura (IARC), bem como 86\% da coleção de cultura microbiológica do mundo estão depositados nesses paises, numa forma clara e acintosa de controle de poder (TERENA, 2003, p. 4-5).
\end{abstract}

Quando a relação entre índios e não índios reproduz a originária prática do colonizador, isto é, a pura exploração de recursos, a comunidade científica perde o potencial de saberes indigenas dificilmente alcançados num relacionamento desleal e utilitarista.

Para as nossas comunidades o conhecimento sobre plantas medicinais, biodiversidade agrícola e o manejo do ecossistema não se separam dos demais aspectos da vida cotidiana, como práticas espirituais, culturais e cosmológicas. Isto significa muito mais que um direito de 'propriedade intelectual' como é usado na economia ocidental, pois a vida não é considerada pelo nosso povo como um objeto comercializável, nem como uma simples mercadoria. Infelizmente, dentro da discussão internacional sobre a 'exploração da biodiversidade' o que tem sido considerado é o controle conhecido como direito de propriedade intelectual e, nessa discussão, não conseguem compreender estas características do sagrado e do espiritual contidas nos conhecimentos dos povos indígenas. Estão dominados por considerações materiais e alienados ao pensamento econômico ocidental - como se a natureza tivesse dono (TERENA, 2003, p. 5).

Essas reflexões aqui propostas visam refletir os caminhos que adotamos e que haveremos de adotar no manejo da história ambiental brasileira. Não há como desprezar certos tipos de enfrentamento inadiáveis, como a questão indigena. E que seja bem menos como o outro, o exótico, e mais como nós, a fim de encontrarmos algumas boas chaves de humanidade que possam galgar o propósito essencial de militância pela manutenção da vida.

\section{Considerações finais}

O protagonismo de uma história ambiental brasileira demandará o desbravamento de inúmeras fontes disponiveis há alguns séculos, apenas esperando ser organizada e tratada pelo historiador. Aqui fizemos breves demonstrações de fontes a fim de sugerir algum ponto de partida com os quais acreditamos potencializar a realização de pesquisas relevantes na área. Mas, talvez a maior contribuição que podemos oferecer neste momento é a preocupação com a forma de abordar história ambiental no Brasil. É imprescindivel que se considere a formação histórica cultural do povo brasileiro para que se possa perceber não apenas que somos todos frutos de três principais matrizes - ameríndia, africana e europeia - como também, constituímos relacionalmente uma so- 
ciedade repleta de complexidades e diferenças que precisam caminhar de maneira construtiva frente às agressões ao meio natural. Por essa razão, privilegiamos uma análise sobre o índio brasileiro, ou melhor, sobre o lugar que a história tradicionalmente o tem colocado. Quem sabe não será a história ambiental a descortinar ainda mais o trabalho já iniciado por historiadores que se dedicaram ao estudo das diversas culturas indígenas? Uma vez que há tanto a aprender sobre a relação homem/natureza com esses povos mais umbilicalmente ligados à terra e possuidores de uma lógica totalmente distinta de uma civilização de mercado e de consumo, razão pela qual nasceram as questões como sustentabilidade e uso racional de recursos. Mas é preciso ir além dos aspectos meramente utilitários. O desafio da história ambiental, ao refletir sobre os saberes de povos tradicionais, como os povos indígenas, poderá ampliar o horizonte desse campo de maneira inovadora e certamente, sua contribuição será auspiciosa.

\section{Referências}

ALMEIDA, Alfredo Wagner Berno de; NAKAZONO, Érica; MARIN, Rosa E. Acevedo; FARIAS JR. Emmanuel de Almeida. Mapeamento social como instrumento de gestão territorial contra o desmatamento e a devastação: processo de capacitação de povos e comunidades tradicionais. In: ALMEIDA, Alfredo Wagner Berno de (org.) et al. Cadernos de debates Nova Cartografia Social: conhecimentos tradicionais na Pan-Amazônia. Manaus: Projeto Nova Cartografia Social da Amazônia/ UEA Edições, 2010. p. 125-126.

ALMEIDA, Alfredo Wagner Berno de; NAKAZONO, Érica; MARIN, Rosa E. Acevedo; FARIAS JR. Emmanuel de Almeida. Universalização e localismo: movimentos sociais e crise dos padrões tradicionais de relação política na Amazônia. In: D'INCAO, Maria Angela; SILVEIRA, Isolda Maciel (org.). A Amazônia e a crise da modernização. Belém: Museu Paraense Emílio Goeldi, 1994. p. 521. https://doi.org/10.32991/2237-2717.2019vgi2.p64-94.

ARRUDA, Gilmar; COLACIOS, Roger. Considerações sobre a ética-politica na História (Ambiental): escalas e o presentismo da devastação. HALAC - Historia Ambiental, Latinoamericana y Caribeña, [S. L.], v. 9, n. 2, p. 64-94, 2019. http//halacsolcha.org/index.php/ halac ISSN 2237.271764.

BECKER, Bertha K. Estado, nação e região no final do século XX. In: D'INCAO, Maria Angela; SILVEIRA, Isolda Maciel (org.). A Amazônia e a crise da modernização Belém: Museu Paraense Emilio Goeldi, 1994. p. 105.
BITTENCOURT, Agnello. Revista Agronômica $\mathrm{N}^{\circ} 12$, set. 1938, Manaus. Economia destructiva. Prof. Agnello Bittencourt (Membro do Conselho Techinico de Economia e Finanças). Artigo dedicado à edição especial de anniversario da "Revista Agronomica". p. 33-34

CARREIRA, Evandro. A consciência cósmica do índio. Brasilia: Senado Federal Centro Gráfico, 1978.

BOURDIEU, Pierre. Os usos sociais da ciência: por uma sociologia clínica do campo científico. Texto revisto pelo autor com a colaboração de Patrick Champagne e Etienne Londais. Traduzido por: Denice Barbara Catani. São Paulo: Editora UNESP, 2004

CANÊDO, Letícia Bicalho. Campo Político. In: CATANI, Afrânio Mendes et al. (org.). Vocabulário Bourdieu. Belo Horizonte: Autêntica Editora, 2017.

CARTAAberta. WANDELLI, Elisa. Disponivel em FREIRE, José Ribamar Bessa. Desculpas Manauaras: a questão ambiental. Taqui Pra Ti. 27 jan 2008. Acesso em: dez 2018.

COSTA, Kelerson Semerene. Homens e natureza na Amazônia brasileira: Dimensões (1616-1920). 2002. 292 f. Tese (Doutorado) - Departamento de História, Universidade de Brasilia, Brasilia, 2002.

DEAN, Warren. O valor da terra nua. In: DEAN, Warren. A ferro e fogo: a história e a devastação da Mata Atlântica brasileira. Traduzido por: Cid Knipel Moreira. Revisão técnica de José Augusto Drummond. São Paulo: Companhia das Letras, 1996. p. 365-380.

DRUMMOND, José Augusto. A História Ambiental: temas, fontes e linhas de pesquisa. Estudos Históricos, Rio de Janeiro, v. 4, n. 8, p. 177-197, 1991

DRUMMOND, José Augusto. Natureza rica, povos pobres? - Questões conceituais e analiticas sobre o papel dos recursos naturais na prosperidade contemporânea. Ambiente \& Sociedade, [S. l.], ano V, n. 10, $1^{\circ}$ sem. 2002. https://doi.org/10.1590/S1414-753X2002000100004.

DRUMMOND, José Augusto. Por que estudar a história ambiental do Brasil? - ensaio temático. Varia História, n. 26, p. 29, jan. 2002.

ESTRELLA do Amazonas. Quinta Feira 9 de agosto de $1855,10{ }^{\circ}$ trimestre. Parte Official. Resolução N ${ }^{\circ} 54$ de 4 de julho de 1855

ESTRELLA do Amazonas. Sabbado 10 de setembro de 1859, 23. ${ }^{\circ}$ trimestre. Parte Official.

FRANCO, José Luiz de Andrade et al. (org.). História Ambiental: fronteiras, recursos naturais e conservação da natureza. Rio de Janeiro: Garamond, 2012. 392p.

FRANCO, José luiz de Andrade; DRUMMOND, José Augusto. O cuidado da natureza: a Fundação Brasileira para a Conservação da Natureza e a experiência conservacionista no Brasil: 1958-1992. Textos de História, Brasília, v. 17, n. 1, p. 59-84, 2009

JORGE, Janes. Tietê, o rio que a cidade perdeu: o Tietê em São Paulo 1890-1940. São Paulo: Alameda, 2006.

KRENAK, Ailton. Ideias para adiar o fim do mundo. São Paulo: Companhia das Letras, 2019. 
LEONARDI. Victor Paes de Barros. Os historiadores e os rios: natureza e ruina na Amazônia Brasileira. Fotos: Juan Pratginestós. Brasilia: Paralelo 15, Editora Universidade de Brasilia, 1999. 272 p.

LIMA, Carla Oliveira de. Historiografia social da Amazônia e história ambiental: um breve balanço. Revista do Lhiste, Porto Alegre, v. 4, n. 6, p. 93, jan./dez. 2017.

MONTEIRO, John Manuel. Tupis, tapuias e historiadores: estudos de historia indigena e do indigenismo. 2001. 233f. Tese (livre-docência) - Universidade Estadual de Campinas, Instituto de Filosofia e Ciências Humanas, Campinas, SP. Disponivel em: http://www.repositorio. unicamp.br/handle/REPOSIP/281350. Acesso em: 4 ago. 2018.

OLIVEIRA. João Rafael Moraes. A luta pela borracha no Brasil e a história ecológica de Warren Dean. Revista Territórios e Fronteiras, [S. l.], v. 3, n. 2, jul./dez. 2010. https://doi.org/10.22228/rt-f.v3i2.71.

PÁDUA, José Augusto. As bases teóricas da história ambiental: dossiê teorias socioambientais. Estudos Avançados, São Paulo, v. 24, n. 68, 2010. https://doi. org/10.1590/S0103-40142010000100009.

PÁDUA, José Augusto. Um sopro de destruição: pensamento político e critica ambiental no Brasil escravista, 1786-1888. Rio de Janeiro: Jorge Zahar Ed., 2002. 318 p.

TERENA, Jorge Miles da Silva. A biodiversidade do ponto de vista de um indio. GTAA, 2003. Disponivel em: https://documentacao.socioambiental.org/documentos/L6D00027.pdf. Acesso em: 08 ago. 2019

TOURAINE, Alain. Critica da Modernidade. 9. ed. Petrópolis, RJ: Vozes, 2009. p. 249.

WORSTER, Donald. Para Fazer História Ambiental. Estudos Históricos, Rio de Janeiro, v. 4, n. 8, p. 198-215, 1991. Traduzido por José Augusto Drummond. p. 201.

\section{Angela Rebelo da Silva Arruda}

Doutoranda em História Social na Universidade Federal do Amazonas (UFAM), em Manaus, AM, Brasil. Bolsista da Coordenação de Aperfeiçoamento de Pessoal de Nivel Superior (CAPES). Professora da Secretaria do Estado de Educação e Qualidade do Ensino (SEDUC) em Manaus, AM, Brasil.

\section{Endereço para correspondência}

Angela Rebelo da Silva Arruda

Universidade Federal do Amazonas

Av. General Rodrigo Octavio Jordão Ramos, 1200, Campus Universitário Senador Arthur Virgílio Filho, setor Norte, bloco Arthur Reis

Coroado I, 69067005

Manaus, AM, Brasil 